\begin{tabular}{|c|c|c|}
\hline \multirow{2}{*}{ IDUNAS } & NATURAL \& APPLIED SCIENCES & 2020 \\
& Vol. 3 \\
No. 2 \\
$(49-63)$
\end{tabular}

\title{
Determination of Exchangeable Cations and Residual Concentration of Herbicide Treated Soils and Analysis of The In-Vitro Biodegradation of The Herbicides
}

\author{
Research Article \\ Sebiomo Adewole ${ }^{1 *(D)}$, Banjo F.Mary \\ ${ }^{l}$ Department of Biological Sciences, Tai Solarin University of Education Ijagun, Ijebu-Ode \\ Author E-mails \\ rev20032002@yahoo.com \\ *Correspondance to: Sebiomo Adewole, Department of Biological Sciences, Tai Solarin University of Education \\ Ijagun, Ijebu-Ode \\ Tel: +2348077675121 \\ DOI: 10.38061/idunas.759008
}

Received:27.06.2020; Accepted:24.11.2020

\section{Abstract}

This study determined the effect of Atrazine, Xtravest, Gramoxone and Glyphosate on exchangeable cations and also analysed the in-vitro biodegradation of this herbicides as well as assayed for their residual concentration in soils. Exchangeable cations were analysed in atomic absorption spectrophotometer. Utilisation of herbicides was determined while herbicide degradation and residual concentration of herbicide were analysed using Gas Chromatography. $\mathrm{K}+, \mathrm{Ca} 2+, \mathrm{Mg} 2+$, and $\mathrm{Na}+$ declined while $\mathrm{Fe} 2+$ and $\mathrm{Zn}+$ accumulated significantly. Bacteria and fungi significantly utilised herbicides as carbon source resulting in herbicide degradation. The lowest herbicide concentration of $118.55 \mathrm{ppm}$ was obtained from atrazine inoculated with bacteria, while the highest herbicide concentration of $449.23 \mathrm{ppm}$ was obtained from xtravest inoculated with fungi. Bacteria and fungi such as: B. subtilis, P. aeruginosa, P. florescences, P. putida, Actinomyces viscous, A. niger, A. tamarii, F. oxysporum, and P. chrysogenum were isolated in all the herbicide treated soils. Continuous herbicide treatment should be avoided because of their ability to persist in soils hence limiting essential nutrients available to plants. Indigenous microorganisms can be employed to remediate soils polluted by herbicides.

Keywords: Cation exchange, Bacteria, Fungi, Herbicide, Biodegradation

\section{INTRODUCTION}

The population is constantly being exposed to increased use of crop protection products. The continual protection of plants and manufacture of synthetic chemicals, such as herbicides, widely contributed to the regularity of the production. However, today the systematic use of herbicides is questioned, with the increasing awareness of the risks, which they can generate for all the components of the environment, even for man health (Tahar et al., 2017). Toxicological consequences due to the exhibition 
in these thousand chemical components by means of the food, water and ground are alarming. The sustainable agriculture involves optimizing agricultural resources and at the same time maintaining the quality of environment and sustaining natural resources. In achieving this optimization, the soil microbial community composition is of great importance, because they play a crucial role in carbon flow, nutrient cycling and litter decomposition, which in turn affect soil fertility and plant growth (Chauhan et al., 2006; Tripathi et al., 2006), and hence occupy a unique position in biological cycles in terrestrial habitat. The soil microbial biomass is considered as active nutrient pool to plants and plays an important role in nutrient cycling and decomposition in ecosystem (De-Lorenzo et al., 2001).

Herbicides are applied to control weeds in the crop field have direct (or) indirect consequences on non-targeted organisms including soil microflora. After application of herbicides, microorganisms are able to degrade and utilize them as energy source for their metabolic activities and also for physiological processes. While processing these activities there may be a chance of change in soil physicochemical characteristics. Diversified effect of both toxic and as well as beneficial effect of herbicides on soil microorganisms and soil characteristics were studied in different ways in the recent past (Trimurtulu et al., 2015).

The continuous use of environmentally persistent herbicides and other synthetic agricultural chemicals posed great risks to soil and water contamination. A viable alternative pesticide that is equally effective and less harmful to the environment is in demand (Souza et al., 2012). The persistence of a pesticide in the soil is defined as the period or extension of time in which it remains active.

There is serious concern about the increased use of herbicides, which may cause (i) environmental hazards such as water table and water body contamination, (ii) biological disruption in crop field populations, and (iii) reduced efficiency as a result of increased population of soil microorganisms more efficient in herbicide degradation. The herbicide that are used frequently eventually reach the soil from the crop plants and accumulates in top $0-15 \mathrm{~cm}$ layer of soil, where the activities of microbes are found to be maximum. Herbicides in the soil affect the non-target and beneficial microorganisms and their activities which are essential for maintaining soil fertility (Sethi et al., 2015).

Atrazine is a selective pre- and post- emergence herbicide providing knockdown and residual action. It has low rate of volatilization from soil and is moderately persistent (half-life of $\sim 60$ days). It is more persistent in neutral and alkaline soils than in soils with low pH. It is moderately mobile and able to be leached through soils into groundwater (Kruger et al., 1996). Metolachlor is a selective herbicide used in the control of grassy weeds in the cultivation of corn, soybeans, peanuts, cotton and other crops. Metolachlor is often used in combination with other broadleaved herbicides (e.g. atrazine, metobromuron and propazine) to extend the spectrum of activity (Ayansina and Oso, 2006). Glyphosate is a broad-spectrum systemic herbicide. It is nonvolatile, it is strongly adsorbed by soil particles and is essentially immobile in soil (AATSE, 2002). Paraquat is a broad-spectrum herbicide that destroys plant tissue by contact action. It is highly soluble in water and because of its ionic properties is strongly adsorbed by soil particles and is essentially immobile in soil. The strong binding of paraquat to clay minerals is the factor most likely associated with its long half-life in soils (Clive, 2006).

Fertilizers, pesticides, herbicides, and some other materials applied to soil often contribute to water and air pollution. Therefore, soil is a key component of environment chemical cycles. Dissolved mineral matter in soil is largely present as ions. Prominent among the cations are $\mathrm{H}+, \mathrm{Ca} 2+, \mathrm{Mg} 2+, \mathrm{K}+, \mathrm{Na}+$ and usually very low levels of $\mathrm{Fe} 2+, \mathrm{Mn} 2+$ and $\mathrm{Al} 3+$. Multivalent cations and anions form ion pairs with each other in soil, solutions (Maynard, 2000). Hence this study determined the effect of selected herbicides (Atrazine, Xtravest, Gramoxone and Glyphosate) on exchangeable cations and also analysed the in-vitro biodegradation of this herbicides as well as assayed for their residual concentration in soils after treatment. 


\section{MATERIALS AND METHODS}

\section{Soil Sampling}

Soil samples were collected from depths of 0-15 cm. Samples were then mixed and homogenized. After removing recognizable plant debris, samples were air-dried and sieved through a 2-mm mesh sieve.

\section{Study Site}

The present study was carried out in the agricultural field located at Oke Odo Street Ago-Iwoye, Nigeria. The soils had no prior pesticide treatment. The site (open field) was divided into fifteen plots (5 $\mathrm{m} 2$ each) of land. The experiment was made up of five treatments which include control (no-treatment) and four herbicide treatments (atrazine, xtravest, glyphosate and gramoxone).

\section{Herbicides}

The herbicides used in this work were provided from a local agricultural dealership store in Ibadan, Nigeria. They were; Xtravest \{atrazine[1-Chloro-3-ethylamino-5-isopropylamino-2,4,6-triazine, C8H14CIN5] + metolachlor [2 -chloro -N- (2-ethyl-6-methylphenyl) -N- (1-methoxypropan-2-yl) acetamide], $\mathrm{C}_{15} \mathrm{H}_{22} \mathrm{CINO}_{2},\{27+15 \%\}$ Suspo (SE) $\}$ (a product of Zhejiang Province Changxing First Chemical Co., Ltd., Xiaopu, Changxing, Zhejiang, China), Glyphosate [2,4-Dichlorophenoxyacetic acid, $\left.\mathrm{C}_{3} \mathrm{H}_{8} \mathrm{NO}_{5} \mathrm{P}\right]$ (Roundup, a product of Monsanto Europe S.A./N.V. Haven 627, Scheldelaan 4602040 Antwerpen Belgium), Gramoxone [1,1-Dimethyl-4,4-bipyridinium dichloride, $\mathrm{C}_{12} \mathrm{H}_{14} \mathrm{C}_{12} \mathrm{~N}_{2}$ ] (Syngenta Crop Protection AG, Basle, Switzerland) and Atrazine [1-Chloro-3-ethylamino-5-isopropylamino-2,4,6triazine, $\mathrm{C}_{8} \mathrm{H}_{14} \mathrm{CIN}_{5}$ ] (Forward (Beihai) Hepu Pesticide Co. Ltd., 1, Quingshuijiang Liangzhou Hepu, Beihai, Guangxi, China, 536100).

\section{Soil Treatments}

The treatments were carried out in triplicates, using the complete randomized block design for a period of 8 weeks; at company recommended rates of 4 1/h (at $350 \mathrm{ml}$ in 151 sprayer). The herbicides were applied successively to the soils every week to the 8th week. Soil samples were then collected every 2 weeks to the 8th week of treatment. Fifteen soil samples were collected in separate polyethene bags every 2 weeks to the 8th week of treatment. A total of sixty soil samples were collected transported immediately to the laboratory for analysis.

\section{Mineral Analysis}

To $2.0 \mathrm{~g}$ of soil sample, $30 \mathrm{ml}$ of IN NH4OAC (ammonium acetate solution) was added and the flasks were shaken on a mechanical shaker for $2 \mathrm{~h} . \mathrm{Ca} 2+, \mathrm{Mg} 2+, \mathrm{K}+, \mathrm{Na}+$ in soil samples were determined using the methods of Blakemore et al. (1987) and USDA, SCS (1972, 1982). Total wet digestion of soil samples in Nitric/Perchloric acid mixtures at ratio 2:1 was used to extract the $\mathrm{Fe} 2+$ and $\mathrm{Zn}+$ from soil samples. Concentrations of $\mathrm{Ca} 2+, \mathrm{K}+, \mathrm{Na}+, \mathrm{Mg} 2+, \mathrm{Fe} 2+$ and $\mathrm{Zn}+$ were determined in Atomic Absorption Spectrophotometer fitted with a hollow cathode lamp and a fuel rich flame (air acetylene), using the methods of Blakemore et al. (1987) and USDA, SCS (1972, 1982). 


\section{Atomic Absorption Spectrophotometry}

The atomic absorption spectrophotometer consisted of a premix burner (water cooled, fishtail type) with a $10 \times 0.05 \mathrm{~cm} 2$ slot. In addition, a monochromator with a diffraction grating of 1800 grooves $/ \mathrm{mm}$, wavelength range of $190-900 \mathrm{~nm}$, focal length of $450 \mathrm{~nm}$ and giving an average dispersion of $1.2 \mathrm{~nm} / \mathrm{mm}$ was positioned. An air- acetylene flame was used with an oxidant pressure of $1.60 \mathrm{~kg} / \mathrm{cm} 2$. As a source of radiation, neon-filled hollow cathode lamps were used. Firstly, a blank solution was run by the instrument to retrieve the background signals. Then standard solutions of each element were measured to optimize the instrument response, and finally sample solutions of soil samples were analyzed in order to determine the concentration of each mineral element. Lead, nickel, cadmium and chromium composition was determined by electro-thermal atomic absorption spectroscopy. The analysis of $\mathrm{Ca} 2+, \mathrm{K}+, \mathrm{Na}+, \mathrm{Mg} 2+, \mathrm{Fe} 2+\mathrm{and} \mathrm{Zn}+$ was done by flame atomic absorption spectroscopy.

\section{Determination of The Concentration of Residual Herbicides in Soils After Treatment Using Gas Chromatography}

The modified method as described by Ayanthi et al. (2008) was used in sample preparation and extraction. The soil samples were homogenised. Extraction was carried out using $10 \mathrm{~g}$ of the sample by adding acetone to sample bound water so that agglomeration of samples during extraction could be minimised, toluene was then added in equal volume of acetone and the samples were agitated using mechanical shaker. The samples were then filtered using vacuum filtration. Acetone was driven off leaving toluene in the mixture. Organic phase was drained using anhydrous sodium sulphate to remove the associated water during extraction. Methanol was added to dissolve the remaining analytes in the solid phase extracted. The filterate of the methanol and toluene phase was added together and then allowed to concentrate to about $2.0 \mathrm{ml}$. The extract was loaded to pre-conditioned C-18 Mega Bond Elut cartridge. The analytes were eluted from the cartridge with ethyl acetate. The extract was collected and then concentrated with nitrogen stream to about $2.0 \mathrm{ml}$ before gas chromatography analysis was used for the analysis. One micro-litre was injected into the Hewlett Packard Gas Chromatography (HP 6890 Powered with HP ChemStation Rev. A 09.01 [1206] Software).

\section{Isolation of Herbicide Utilizing Bacteria and Fungi}

Five grams of each soil sample was suspended in 250-ml Erlenmeyer flasks containing a mixture of $50 \mathrm{ml}$ of mineral salts medium and $1 \mathrm{ml}$ of each herbicide in separate flasks. This concentration was used because it is equivalent to the field application rate. The flasks were incubated on a rotary shaker (Gallenkamp, England) at $120 \mathrm{rpm}$ for 7 days at $30^{\circ} \mathrm{C}$. Isolation was then carried out using the spread plate method on the solid mineral salts medium with each herbicide added to separate plates. The plates were incubated at $30^{\circ} \mathrm{C}$ for 5 days for bacteria and $30^{\circ} \mathrm{C}$ for 7 days for fungi. Morphologically distinct colonies of indigenous microbial isolates of bacteria and fungi isolated on nutrient agar for bacteria and potato dextrose agar for fungi respectively were used in the herbicide utilization experiments. Identity of the bacterial isolates was affirmed after characterization by standard bacteriological methods (Holt et al., 1994; Cheesbrough, 1984) while the fungal isolates were identified using morphological and cultural characteristics.

\section{Determination of the Abilities of Bacteria and Fungi to Utilize Selected Herbicides}

The ability of microbial isolates (bacterial consortium and fungal consortium) to utilise herbicide substrates as carbon source (atrazine, xtravest, glyphosate and gramoxone) in pure cultures were determined in minimal salt medium (g/l) (Moneke et al., 2010). The components were dissolved in 1000ml distilled 
water, homogenized on hot plate magnetic stirrer to form uniform solution for $30 \mathrm{~min}$. The $\mathrm{pH}$ of the basal medium was adjusted to $\mathrm{pH}$ 7.2. The basal medium of $150 \mathrm{ml}$ was dispensed into $250 \mathrm{ml}$ Erlenmeyer flasks and herbicide substrates were introduced into each flask respectively at $100 \mathrm{ppm}$ after sterilisation which was done separately in an autoclave at $121^{\circ} \mathrm{C}$ for $15 \mathrm{~min}$ and cooled to ambient temperature. One ml aliquot of diluted overnight broth cultures of each test organisms $\left(\times 10^{4}\right.$ cells $\left./ \mathrm{ml}\right)$ were seeded into each flask respectively and the flasks were incubated in a gyratory shaker incubator at $150 \mathrm{rpm}$ for a period of thirty days at $30^{\circ} \mathrm{C}$ (Bacterial isolates used in this study were those that had the highest turbidity, while the fungal isolates used in this study were those that had the highest counts on each of the herbicides). Utilisation of herbicides by microbial isolates were evaluated by monitoring bacterial and fungal growth using viable count on nutrient and potato dextrose agars, fungal dry-weights, optical density of bacteria and $\mathrm{pH}$.

\section{Determination of in-vitro Biodegradation of Herbicides by Bacteria and Fungi}

The ability of herbicide degrading bacteria and fungi to degrade pure herbicide substrates was tested in minimal salt medium in $100 \mathrm{ml}$ flasks using the method of Moneke et al. (2010). The flasks were then autoclaved and inoculated with $1.0 \mathrm{ml}$ portion of each isolate (except one which serves as control). The flasks were subsequently incubated in an orbital shaker incubator at $150 \mathrm{rev} / \mathrm{min}$ at $30^{\circ} \mathrm{C}$ for 7 days. Gas chromatography analysis was then used to determine the remaining herbicide after 7 days of incubation, in the orbital shaker incubator, using the method of Ayanthi et al. (2008) already described above.

\section{Statistical Analysis}

The data were statistically analysed, with SPSS 20 software, using a one-way analysis of variance (ANOVA). Means were compared at 5\% level of significance using Duncan's multiple range test.

\section{RESULTS}

Pseudomonas spp and Bacillus spp were found to be of common occurrence in herbicide treated soils. B. subtilis, P. aeruginosa, P. florescences, $P$. putida and Actinomyces viscous were isolated in all the herbicide treated soils. Meanwhile fungi such as Aspergillus, Fusarium and Penicillum species were of common occurrence in all the herbicide treated soils. A. niger, A. tamarii, $F$. oxysporum, and $P$. chrysogenum were isolated in all the herbicide treated soils.

\section{Microbiological and Physicochemical Properties of Soil at the Experimental Site}

Presented in Table 1 are the microbiological and physicochemical properties of the soil at the experimental site before treatment with herbicides. Table 2 shows the effect of herbicide treatment on exchangeable $\mathrm{Ca}^{2+}, \mathrm{Mg}^{2+}, \mathrm{K}^{+}, \mathrm{Na}^{+}, \mathrm{Fe}^{2+}$ and $\mathrm{Zn}^{+}$in soil samples.

Table 1: Microbiological and physicochemical properties of soil at the experimental site

\begin{tabular}{lc}
\hline Soil properties & Values \\
\hline Soil type & Ferric luvisols \\
Bacterial count $\left(\mathrm{CFU} / \mathrm{g} \times 10^{5}\right)$ & 9.70 \\
Fungal count $\left(\mathrm{CFU} / \mathrm{g} \times 10^{5}\right)$ & 1.10 \\
Actinomycetes count $\left(\mathrm{CFU} / \mathrm{g} \times 10^{5}\right)$ & 0.80 \\
Total nitrogen $(\%)$ & 0.12 \\
Available phosphorus $(\mathrm{ppm})$ & 10.0 \\
Organic carbon $(\%)$ & 1.42 \\
Sodium $(\mathrm{Na})\left(\mathrm{cmolkg}^{-1}\right)$ & 0.42 \\
Potassium $(\mathrm{K})\left(\mathrm{cmolkg}^{-1}\right)$ & 0.44
\end{tabular}




\begin{tabular}{lc} 
Calcium $\left(\mathrm{cmolkg}^{-1}\right)$ & 4.62 \\
Magnesium $(\mathrm{Mg})\left(\mathrm{cmolkg}^{-1}\right)$ & 1.41 \\
Iron $(\mathrm{Fe})\left(\mathrm{cmolkg}^{-1}\right)$ & 1820 \\
Zinc $(\mathrm{Zn})\left(\mathrm{cmolkg}^{-1}\right)$ & 19 \\
Soil electrical conductivity & \\
$(\mu \mathrm{S} / \mathrm{cm})$ & 250 \\
$\mathrm{pH}$ & 6.80 \\
Soil moisture $(\%)$ & 18.32 \\
Sand $(\%)$ & 67.6 \\
Silt $(\%)$ & 20 \\
Clay $(\%)$ & 12.4 \\
\hline
\end{tabular}

\section{Exchangeable Cations (cmolkg-1) of Soil Samples Obtained at the 2nd, 4th, 6th, and 8th Weeks of Herbicide Treatment}

Exchangeable $\mathrm{Na}^{+}$declined considerably in atrazine, gramoxone and xtravest treated soils from the $2^{\text {nd }}$ to the $8^{\text {th }}$ week. Glyphosate treated soils had the highest exchangeable $\mathrm{Na}^{+}$content of $0.67 \mathrm{cmolkg}^{-1}$ at the $6^{\text {th }}$ week, while soils treated with gramoxone recorded the lowest exchangeable $\mathrm{Na}^{+}$value of 0.19 cmolkg $^{-1}$ at the $8^{\text {th }}$ week. In glyphosate treated soils exchangeable $\mathrm{K}^{+}$accumulated from the $2^{\text {nd }}(0.78$ cmolkg $\left.^{-1}\right)$ to the $6^{\text {th }}\left(1.31 \mathrm{cmolkg}^{-1}\right)$ weeks of treatment. Glyphosate treated soils had the highest exchangeable $\mathrm{K}^{+}$value of $1.31 \mathrm{cmolkg}^{-1}$ at the $6^{\text {th }}$ week while gramoxone treated soil samples recorded the lowest exchangeable $\mathrm{K}^{+}$value of $0.1 \mathrm{cmolkg}^{-1}$ at the $8^{\text {th }}$ week of treatment (Table 2). Soils treated with atrazine recorded the highest exchangeable $\mathrm{Ca}^{2+}$ value of $8.44 \mathrm{cmolkg}^{-1}$ at the $6^{\text {th }}$ week of treatment while soils treated with glyphosate and gramoxone had the lowest calcium content value of $3.27 \mathrm{cmolkg}^{-1}$ at the $4^{\text {th }}$ week of treatment (Table 2). Statistical analysis showed that treatment with the herbicide types resulted in significant changes at the $2^{\text {nd }}(p \leq 0.001), 4^{\text {th }}(p \leq 0.004), 6^{\text {th }}(p \leq 0.000)$ and $8^{\text {th }}(p \leq 0.000)$ weeks, in values of exchangeable $\mathrm{Mg}^{2+}$. Glyphosate treated soils had the lowest exchangeable $\mathrm{Fe}^{2+}$ value of $2643 \mathrm{cmolkg}^{-1}$ while gramoxone treated soils had the highest exchangeable $\mathrm{Fe}^{2+}$ value of $5862 \mathrm{cmolkg}^{-1}$ at the $2^{\text {nd }}$ week. Soils treated with glyphosate had the highest exchangeable $\mathrm{Zn}^{+}$value of $81.77 \mathrm{cmolkg}^{-1}$ at the $8^{\text {th }}$ week of treatment. Glyphosate and xtravest treated soils had the lowest value of $29 \mathrm{cmolkg}^{-1}$ at the $2^{\text {nd }}$ week of treatment (Table 2).

Table 2: Exchangeable cations $\left(\mathrm{cmolkg}^{-1}\right)$ of soil samples obtained at the $2^{\text {nd }}, 4^{\text {th }}, 6^{\text {th }}$, and $8^{\text {th }}$ weeks of herbicide treatment

\begin{tabular}{llllll}
\hline & & $2^{\mathrm{ND}} \mathrm{WK}$ & $4^{\mathrm{TH}} \mathrm{WK}$ & $6^{\mathrm{TH}} \mathrm{WK}$ & $8^{\mathrm{TH}} \mathrm{WK}$ \\
\hline $\mathrm{Na}$ & CON & $0.480 \pm 0.017^{\mathrm{bc}}$ & $0.550 \pm 0.075^{\mathrm{b}}$ & $0.440 \pm 0.015^{\mathrm{b}}$ & $0.280 \pm 0.017^{\mathrm{b}}$ \\
& GLY & $0.550 \pm 0.003^{\mathrm{c}}$ & $0.560 \pm 0.015^{\mathrm{b}}$ & $0.670 \pm 0.031^{\mathrm{c}}$ & $0.430 \pm 0.019^{\mathrm{c}}$ \\
& ATR & $0.420 \pm 0.009^{\mathrm{a}}$ & $0.260 \pm 0.009^{\mathrm{a}}$ & $0.260 \pm 0.018^{\mathrm{a}}$ & $0.220 \pm 0.006^{\mathrm{a}}$ \\
& GRA & $0.480 \pm 0.007^{\mathrm{b}}$ & $0.360 \pm 0.006^{\mathrm{a}}$ & $0.300 \pm 0.015^{\mathrm{a}}$ & $0.190 \pm 0.015^{\mathrm{a}}$ \\
& XTR & $0.490 \pm 0.015^{\mathrm{b}}$ & $0.330 \pm 0.015^{\mathrm{a}}$ & $0.280 \pm 0.009^{\mathrm{a}}$ & $0.210 \pm 0.003^{\mathrm{a}}$ \\
$\mathrm{K}$ & CON & $0.480 \pm 0.023^{\mathrm{b}}$ & $0.460 \pm 0.006^{\mathrm{c}}$ & $0.600 \pm 0.029^{\mathrm{b}}$ & $0.420 \pm 0.009^{\mathrm{b}}$ \\
& GLY & $0.780 \pm 0.012^{\mathrm{c}}$ & $0.880 \pm 0.009^{\mathrm{d}}$ & $1.310 \pm 0.047^{\mathrm{c}}$ & $0.800 \pm 0.032^{\mathrm{c}}$ \\
& ATR & $0.280 \pm 0.000^{\mathrm{a}}$ & $0.190 \pm 0.015 \mathrm{a}$ & $0.270 \pm 0.006^{\mathrm{a}}$ & $0.120 \pm 0.020^{\mathrm{a}}$ \\
& GRA & $0.510 \pm 0.012^{\mathrm{b}}$ & $0.230 \pm 0.021^{\mathrm{b}}$ & $0.200 \pm 0.015^{\mathrm{a}}$ & $0.100 \pm 0.007^{\mathrm{a}}$ \\
& XTR & $0.500 \pm 0.015^{\mathrm{b}}$ & $0.430 \pm 0.000^{\mathrm{c}}$ & $0.250 \pm 0.021^{\mathrm{a}}$ & $0.140 \pm 0.012^{\mathrm{a}}$ \\
$\mathrm{Ca}$ & CON & $4.730 \pm 0.121^{\mathrm{a}}$ & $4.140 \pm 0.020^{\mathrm{c}}$ & $7.680 \pm 0.277^{\mathrm{c}}$ & $6.730 \pm 0.064^{\mathrm{b}}$ \\
& GLY & $4.960 \pm 0.037^{\mathrm{a}}$ & $3.270 \pm 0.038^{\mathrm{a}}$ & $5.650 \pm 0.165^{\mathrm{a}}$ & $6.070 \pm 0.035^{\mathrm{a}}$ \\
& ATR & $4.710 \pm 0.055^{\mathrm{a}}$ & $3.320 \pm 0.064^{\mathrm{a}}$ & $8.440 \pm 0.009^{\mathrm{d}}$ & $6.620 \pm 0.118^{\mathrm{b}}$
\end{tabular}




\begin{tabular}{llllll} 
& GRA & $5.130 \pm 0.121^{\mathrm{a}}$ & $3.270 \pm 0.038^{\mathrm{a}}$ & $6.790 \pm 0.105^{\mathrm{b}}$ & $6.080 \pm 0.064^{\mathrm{a}}$ \\
& XTR & $4.100 \pm 0.078^{\mathrm{a}}$ & $4.010 \pm 0.009^{\mathrm{b}}$ & $6.860 \pm 0.032^{\mathrm{b}}$ & $6.310 \pm 0.055^{\mathrm{a}}$ \\
$\mathrm{Mg}$ & CON & $1.480 \pm 0.003^{\mathrm{c}}$ & $0.970 \pm 0.072^{\mathrm{b}}$ & $1.990 \pm 0.006^{\mathrm{c}}$ & $1.800 \pm 0.020^{\mathrm{c}}$ \\
& GLY & $1.430 \pm 0.010^{\mathrm{bc}}$ & $0.940 \pm 0.012^{\mathrm{b}}$ & $2.720 \pm 0.092^{\mathrm{d}}$ & $1.930 \pm 0.037^{\mathrm{d}}$ \\
& ATR & $1.400 \pm 0.012^{\mathrm{b}}$ & $0.780 \pm 0.061^{\mathrm{a}}$ & $1.520 \pm 0.006^{\mathrm{b}}$ & $1.360 \pm 0.050^{\mathrm{a}}$ \\
& GRA & $1.490 \pm 0.026^{\mathrm{c}}$ & $0.770 \pm 0.012^{\mathrm{a}}$ & $1.140 \pm 0.064^{\mathrm{a}}$ & $1.380 \pm 0.040^{\mathrm{a}}$ \\
& XTR & $1.330 \pm 0.029^{\mathrm{a}}$ & $1.040 \pm 0.000^{\mathrm{b}}$ & $1.430 \pm 0.069^{\mathrm{b}}$ & $1.500 \pm 0.028^{\mathrm{b}}$ \\
$\mathrm{Fe}$ & CON & $1956 \pm 182^{\mathrm{a}}$ & $3976 \pm 183^{\mathrm{a}}$ & $5031 \pm 223^{\mathrm{c}}$ & $4990 \pm 491^{\mathrm{a}}$ \\
& GLY & $2643 \pm 44^{\mathrm{a}}$ & $4049 \pm 104^{\mathrm{a}}$ & $4283 \pm 85^{\mathrm{ab}}$ & $4926 \pm 6^{\mathrm{a}}$ \\
& ATR & $4087 \pm 441^{\mathrm{b}}$ & $4463 \pm 60^{\mathrm{b}}$ & $3888 \pm 165^{\mathrm{a}}$ & $4605 \pm 77^{\mathrm{a}}$ \\
& GRA & $5862 \pm 512^{\mathrm{c}}$ & $4579 \pm 68^{\mathrm{b}}$ & $4698 \pm 34^{\mathrm{bc}}$ & $5348 \pm 204^{\mathrm{a}}$ \\
& XTR & $5216 \pm 379^{\mathrm{c}}$ & $4666 \pm 65^{\mathrm{b}}$ & $5002 \pm 55^{\mathrm{c}}$ & $4933 \pm 150^{\mathrm{a}}$ \\
$\mathrm{Zn}$ & CON & $28.670 \pm 0.880^{\mathrm{a}}$ & $40.670 \pm 2.030^{\mathrm{a}}$ & $69.670 \pm 0.880^{\mathrm{d}}$ & $90.000 \pm 2.020^{\mathrm{e}}$ \\
& GLY & $29.000 \pm 0.580^{\mathrm{a}}$ & $41.670 \pm 1.450^{\mathrm{a}}$ & $63.000 \pm 0.580^{\mathrm{c}}$ & $81.770 \pm 1.590^{\mathrm{d}}$ \\
& ATR & $31.000 \pm 0.580^{\mathrm{a}}$ & $62.670 \pm 2.030^{\mathrm{b}}$ & $57.000 \pm 2.000^{\mathrm{b}}$ & $61.270 \pm 1.300^{\mathrm{b}}$ \\
& GRA & $44.670 \pm 1.450^{\mathrm{b}}$ & $62.770 \pm 0.720^{\mathrm{b}}$ & $46.930 \pm 1.440^{\mathrm{a}}$ & $44.270 \pm 0.720^{\mathrm{a}}$ \\
& XTR & $29.000 \pm 1.730^{\mathrm{a}}$ & $67.770 \pm 1.010^{\mathrm{c}}$ & $65.000 \pm 0.000^{\mathrm{c}}$ & $73.000 \pm 1.150^{\mathrm{c}}$ \\
\hline
\end{tabular}

$\mathrm{CON}=$ Control, GLY= Glyphosate, $\mathrm{ATR}=$ Atrazine, GRA= Gramoxone, XTR= Xtravest, WK=Week. Columns with values that have the same letter show that there are no significant differences $(\mathrm{p} \geq 0.05)$ between the values; columns with values that have different letters show that there is a significant difference $(\mathrm{p} \leq 0.05)$ between the values.

\section{Changes in Viable Counts $\left([\mathrm{CFU} / \mathrm{g}] \times 10^{5}\right)$ of Bacteria During Biodegradation}

There were significant increases $(\mathrm{p} \leq 0.000)$ in viable counts from the $2^{\text {nd }}$ to the $12^{\text {th }}$ day and at the $14^{\text {th }}$ day $(\mathrm{p} \leq 0.001)$ at the $2^{\text {nd }}$ week. Glyphosate had the highest viable count value of $10.80 \times 10^{5} \mathrm{CFU} / \mathrm{g}$ at the $6^{\text {th }}$ day of incubation, while xtravest recorded the lowest viable count value of $6.37 \times 10^{5} \mathrm{CFU} / \mathrm{g}$ at the $14^{\text {th }}$ day (Table 3). Xtravest had lower viable count values between the $8^{\text {th }}$ and $14^{\text {th }}$ day compared to the control. Although all viable count values at the $2^{\text {nd }}$ week dropped from the $6^{\text {th }}$ to the $14^{\text {th }}$ day. Glyphosate recorded the highest viable count of $12.76 \times 10^{5} \mathrm{CFU} / \mathrm{g}$ at the $10^{\text {th }}$ day of incubation (Table 3). Control soil samples had lower viable count values than those of the herbicides.

\section{Changes in Optical Density of Bacteria During Biodegradation}

Optical density values increased significantly $(\mathrm{p} \leq 0.000)$ from the $2^{\text {nd }}$ to the $14^{\text {th }}$ day at the $2^{\text {nd }}$ week. Gramoxone had the lowest optical density value of 0.885 and 0.955 at the $2^{\text {nd }}$ and $14^{\text {th }}$ days of incubation respectively at the $8^{\text {th }}$ week herbicide types had significant effect $(\mathrm{p} \leq 0.000)$ on optical density values from the $2^{\text {nd }}$ to the $14^{\text {th }}$ day. Optical density values for control and glyphosate reduced from the $2^{\text {nd }}$ to the $14^{\text {th }}$ day. Xtravest had the highest optical density value of 0.974 at the $14^{\text {th }}$ day of incubation. Atrazine had the lowest optical density value of 0.913 at the $2^{\text {nd }}$ day of incubation, while at the $14^{\text {th }}$ day of incubation glyphosate had the lowest optical density value of 0.929 (Table 4). 
Table 3: Changes in viable counts $\left([\mathrm{CFU} / \mathrm{g}] \times 10^{5}\right)$ of bacteria during biodegradation

\begin{tabular}{|c|c|c|c|c|c|c|c|c|}
\hline & & $2^{\mathrm{ND}}$ & $4^{\mathrm{TH}}$ & $6^{\mathrm{TH}}$ & $8^{\mathrm{TH}}$ & $10^{\mathrm{TH}}$ & $12^{\mathrm{TH}}$ & $14^{\mathrm{TH}}$ \\
\hline \multirow[t]{4}{*}{$2^{\mathrm{ND}} \mathrm{WK}$} & $\mathrm{CON}$ & $8.17 \pm 0.033^{\mathrm{a}}$ & $8.57 \pm 0.033^{\mathrm{a}}$ & $8.75 \pm 0.003^{\mathrm{a}}$ & $7.37 \pm 0.088^{a}$ & $6.63 \pm 0.133^{a}$ & $6.84 \pm 0.003^{b}$ & $6.76 \pm 0.019^{\mathrm{ab}}$ \\
\hline & GLY & $10.33 \pm 0.067^{e}$ & $10.65 \pm 0.029^{\mathrm{e}}$ & $10.80 \pm 0.000^{\mathrm{e}}$ & $9.60 \pm 0.000^{d}$ & $8.20 \pm 0.118^{c}$ & $7.85 \pm 0.087^{d}$ & $7.38 \pm 0.053^{c}$ \\
\hline & XTR & $8.65 \pm 0.047^{b}$ & $8.72 \pm 0.017^{b}$ & $8.94 \pm 0.020^{\mathrm{b}}$ & $7.28 \pm 0.600^{\mathrm{a}}$ & $6.53 \pm 0.203^{a}$ & $6.43 \pm 0.203^{a}$ & $6.37 \pm 0.233^{2}$ \\
\hline & GRA & $9.33 \pm 0.067^{c}$ & $9.81 \pm 0.007^{c}$ & $9.90 \pm 0.000^{c}$ & $8.50 \pm 0.000^{c}$ & $7.66 \pm 0.030^{\mathrm{b}}$ & $7.54 \pm 0.037^{\mathrm{cd}}$ & $7.43 \pm 0.033^{c}$ \\
\hline \multirow{3}{*}{$4^{\mathrm{TH}} \mathrm{WK}$} & ATR & $9.81 \pm 0.007^{c}$ & $10.03 \pm 0.033^{c}$ & $10.41 \pm 0.007^{\mathrm{d}}$ & $9.22 \pm 0.012^{d}$ & $8.55 \pm 0.029^{d}$ & $8.37 \pm 0.033^{d}$ & $8.03 \pm 0.033^{e}$ \\
\hline & XTR & $8.41 \pm 0.007^{\mathrm{a}}$ & $8.87 \pm 0.067^{\mathrm{a}}$ & $9.22 \pm 0.017^{\mathrm{b}}$ & $8.13 \pm 0.033^{c}$ & $7.23 \pm 0.088^{b}$ & $6.89 \pm 0.047^{b}$ & $6.37 \pm 0.035^{b}$ \\
\hline & GRA & $9.10 \pm 0.058^{b}$ & $9.38 \pm 0.017^{b}$ & $9.67 \pm 0.017^{c}$ & $7.57 \pm 0.145^{b}$ & $7.10 \pm 0.153^{b}$ & $6.43 \pm 0.120^{\mathrm{a}}$ & $6.10 \pm 0.058^{a}$ \\
\hline \multirow[t]{2}{*}{$6^{\mathrm{TH}} \mathrm{WK}$} & $\mathrm{CON}$ & $7.33 \pm 0.033^{\mathrm{a}}$ & $7.43 \pm 0.033^{\mathrm{a}}$ & $7.57 \pm 0.033^{\mathrm{a}}$ & $7.63 \pm 0.033^{\mathrm{a}}$ & $7.70 \pm 0.058^{a}$ & $7.57 \pm 0.033^{\mathrm{a}}$ & $7.37 \pm 0.033^{a}$ \\
\hline & GLY & $11.33 \pm 0.176^{\mathrm{d}}$ & $11.41 \pm 0.174^{d}$ & $11.50 \pm 0.173^{\mathrm{d}}$ & $11.60 \pm 0.173^{\mathrm{d}}$ & $11.67 \pm 0.145^{\mathrm{d}}$ & $11.57 \pm 0.145^{\mathrm{d}}$ & $11.3 \pm 0.058^{d}$ \\
\hline \multirow[t]{5}{*}{$8^{\mathrm{TH}} \mathrm{WK}$} & $\mathrm{CON}$ & $7.50 \pm 0.000^{\mathrm{a}}$ & $7.57 \pm 0.033^{\mathrm{a}}$ & $7.67 \pm 0.033^{\mathrm{a}}$ & $7.83 \pm 0.033^{\mathrm{a}}$ & $7.83 \pm 0.033^{\mathrm{a}}$ & $7.67 \pm 0.033^{\mathrm{a}}$ & $7.37 \pm 0.033^{2}$ \\
\hline & GLY & $12.23 \pm 0.145^{\mathrm{e}}$ & $12.37 \pm 0.145^{\mathrm{e}}$ & $12.47 \pm 0.133^{\mathrm{e}}$ & $12.67 \pm 0.033^{\mathrm{e}}$ & $12.77 \pm 0.033^{\mathrm{e}}$ & $12.53 \pm 0.033^{\mathrm{e}}$ & $12.17 \pm 0.033^{d}$ \\
\hline & ATR & $10.57 \pm 0.088^{c}$ & $10.60 \pm 0.058^{c}$ & $10.70 \pm 0.000^{c}$ & $10.87 \pm 0.033^{c}$ & $11.00 \pm 0.058^{c}$ & $10.67 \pm 0.176^{c}$ & $9.67 \pm 0.176^{c}$ \\
\hline & XTR & $9.33 \pm 0.067^{b}$ & $9.57 \pm 0.088^{b}$ & $9.67 \pm 0.088^{b}$ & $9.80 \pm 0.058^{b}$ & $9.83 \pm 0.033^{b}$ & $9.60 \pm 0.000^{b}$ & $9.07 \pm 0.033^{b}$ \\
\hline & GRA & $10.83 \pm 0.033^{d}$ & $10.90 \pm 0.000^{d}$ & $11.00 \pm 0.000^{d}$ & $11.47 \pm 0.033^{d}$ & $11.60 \pm 0.058^{d}$ & $11.00 \pm 0.000^{d}$ & $9.90 \pm 0.058^{c}$ \\
\hline
\end{tabular}

$\mathrm{CON}=$ Control, GLY= Glyphosate, ATR= Atrazine, GRA= Gramoxone, XTR= Xtravest, WK=Week. Columns with values that have the same letter show that there are no significant differences $(\mathrm{p} \geq 0.05)$ between the values; columns with values that have different letters show that there is a significant difference ( $\mathrm{P} \leq 0.05$ ) between the values.

Table 4: Changes in optical density of bacteria during biodegradation

\begin{tabular}{|c|c|c|c|c|c|c|c|c|}
\hline & & $2^{\mathrm{ND}}$ & $4^{\mathrm{TH}}$ & $6^{\mathrm{TH}}$ & $8^{\mathrm{TH}}$ & $10^{\mathrm{TH}}$ & $12^{\mathrm{TH}}$ & $14^{\mathrm{TH}}$ \\
\hline \multirow[t]{5}{*}{$2^{\mathrm{ND}} \mathrm{WK}$} & $\mathrm{CON}$ & $0.882 \pm 0.001^{2}$ & $0.886 \pm 0.001^{\mathrm{a}}$ & $0.891 \pm 0.001^{\mathrm{a}}$ & $0.893 \pm 0.001^{\mathrm{a}}$ & $0.894 \pm 0.001^{\mathrm{a}}$ & $0.896 \pm 0.001^{\mathrm{a}}$ & $0.898 \pm 0.001^{\mathrm{a}}$ \\
\hline & GLY & $0.941 \pm 0.001^{b}$ & $0.945 \pm 0.001^{\mathrm{c}}$ & $0.956 \pm 0.001^{\mathrm{c}}$ & $0.961 \pm 0.001^{c}$ & $0.971 \pm 0.001^{\mathrm{d}}$ & $0.976 \pm 0.002^{c}$ & $0.984 \pm 0.003 \mathrm{c}$ \\
\hline & ATR & $0.894 \pm 0.001^{2}$ & $0.903 \pm 0.003^{b}$ & $0.924 \pm 0.000^{\mathrm{b}}$ & $0.941 \pm 0.001^{b}$ & $0.961 \pm 0.001^{\mathrm{c}}$ & $0.970 \pm 0.002^{c}$ & $0.985 \pm 0.003 \mathrm{c}$ \\
\hline & XTR & $0.954 \pm 0.002^{c}$ & $0.965 \pm 0.001^{\mathrm{d}}$ & $0.975 \pm 0.001^{\mathrm{d}}$ & $0.983 \pm 0.001^{\mathrm{d}}$ & $1.043 \pm 0.001^{\mathrm{e}}$ & $1.045 \pm 0.001^{\mathrm{d}}$ & $1.046 \pm 0.001^{\mathrm{d}}$ \\
\hline & GRA & $0.885 \pm 0.008^{2}$ & $0.887 \pm 0.001^{\mathrm{a}}$ & $0.892 \pm 0.001^{\mathrm{a}}$ & $0.895 \pm 0.001^{\mathrm{a}}$ & $0.917 \pm 0.003^{b}$ & $0.938 \pm 0.004^{b}$ & $0.955 \pm 0.003^{b}$ \\
\hline \multirow[t]{5}{*}{$4^{\mathrm{TH}} \mathrm{WK}$} & $\mathrm{CON}$ & $0.881 \pm 0.001^{2}$ & $0.888 \pm 0.000^{\mathrm{a}}$ & $0.893 \pm 0.001^{\mathrm{a}}$ & $0.895 \pm 0.001^{\mathrm{a}}$ & $0.895 \pm 0.001^{\mathrm{d}}$ & $0.898 \pm 0.001^{\mathrm{a}}$ & $0.910 \pm 0.006^{\mathrm{a}}$ \\
\hline & GLY & $0.945 \pm 0.001^{c}$ & $0.947 \pm 0.001^{\mathrm{c}}$ & $0.961 \pm 0.002^{c}$ & $0.965 \pm 0.001^{c}$ & $0.975 \pm 0.001^{\mathrm{d}}$ & $0.977 \pm 0.001^{d}$ & $0.981 \pm 0.001^{\mathrm{d}}$ \\
\hline & ATR & $0.897 \pm 0.001^{b}$ & $0.909 \pm 0.003^{b}$ & $0.928 \pm 0.001^{b}$ & $0.945 \pm 0.001^{b}$ & $0.963 \pm 0.001^{\mathrm{c}}$ & $0.967 \pm 0.002^{c}$ & $0.969 \pm 0.002^{c}$ \\
\hline & XTR & $0.956 \pm 0.002^{\mathrm{d}}$ & $0.956 \pm 0.002^{\mathrm{d}}$ & $0.977 \pm 0.001^{\mathrm{d}}$ & $0.986 \pm 0.000^{d}$ & $1.047 \pm 0.001^{\mathrm{e}}$ & $1.138 \pm 0.001^{\mathrm{e}}$ & $1.143 \pm 0.002^{\mathrm{e}}$ \\
\hline & GRA & $0.887 \pm 0.007^{\mathrm{ab}}$ & $0.887 \pm 0.007^{\mathrm{a}}$ & $0.894 \pm 0.001^{\mathrm{a}}$ & $0.896 \pm 0.001^{\mathrm{a}}$ & $0.925 \pm 0.004^{b}$ & $0.931 \pm 0.004^{b}$ & $0.939 \pm 0.003^{b}$ \\
\hline \multirow[t]{5}{*}{$6^{\mathrm{TH}} \mathrm{WK}$} & $\mathrm{CON}$ & $0.885 \pm 0.001^{2}$ & $0.887 \pm 0.001^{\mathrm{a}}$ & $0.890 \pm 0.001^{\mathrm{a}}$ & $0.892 \pm 0.001^{\mathrm{a}}$ & $0.898 \pm 0.001^{\mathrm{a}}$ & $0.993 \pm 0.001^{c}$ & $1.086 \pm 0.031^{\mathrm{a}}$ \\
\hline & GLY & $0.946 \pm 0.002^{d}$ & $0.949 \pm 0.003^{\mathrm{d}}$ & $0.952 \pm 0.003^{\mathrm{d}}$ & $0.954 \pm 0.003^{c}$ & $0.960 \pm 0.003 \mathrm{c}$ & $0.965 \pm 0.002^{2 b}$ & $1.357 \pm 0.027^{b}$ \\
\hline & ATR & $0.907 \pm 0.004^{b}$ & $0.915 \pm 0.001^{b}$ & $0.920 \pm 0.001^{b}$ & $0.930 \pm 0.001^{b}$ & $0.942 \pm 0.001^{b}$ & $0.971 \pm 0.004^{b}$ & $1.426 \pm 0.003 \mathrm{c}$ \\
\hline & XTR & $0.964 \pm 0.002^{e}$ & $0.967 \pm 0.001^{\mathrm{e}}$ & $0.968 \pm 0.001^{\mathrm{e}}$ & $0.972 \pm 0.001^{\mathrm{d}}$ & $0.976 \pm 0.001^{\mathrm{d}}$ & $0.988 \pm 0.001^{c}$ & $1.465 \pm 0.002^{c}$ \\
\hline & GRA & $0.934 \pm 0.007 \mathrm{c}$ & $0.937 \pm 0.007 \mathrm{c}$ & $0.939 \pm 0.006^{c}$ & $0.936 \pm 0.003^{b}$ & $0.943 \pm 0.003^{b}$ & $0.956 \pm 0.004^{\mathrm{a}}$ & $1.330 \pm 0.006^{b}$ \\
\hline \multirow[t]{5}{*}{$8^{\mathrm{TH} W K}$} & $\mathrm{CON}$ & $0.980 \pm 0.000^{\mathrm{e}}$ & $0.980 \pm 0.000^{\mathrm{e}}$ & $0.977 \pm 0.002^{\mathrm{e}}$ & $0.970 \pm 0.000^{\mathrm{d}}$ & $0.970 \pm 0.000^{\mathrm{d}}$ & $0.961 \pm 0.001^{\mathrm{d}}$ & $0.961 \pm 0.001^{\mathrm{d}}$ \\
\hline & GLY & $0.951 \pm 0.001^{c}$ & $0.950 \pm 0.000^{c}$ & $0.950 \pm 0.000^{c}$ & $0.941 \pm 0.001^{b}$ & $0.938 \pm 0.001^{b}$ & $0.931 \pm 0.001^{\mathrm{a}}$ & $0.929 \pm 0.001^{\mathrm{a}}$ \\
\hline & ATR & $0.913 \pm 0.004^{2}$ & $0.917 \pm 0.002^{\mathrm{a}}$ & $0.925 \pm 0.001^{\mathrm{a}}$ & $0.927 \pm 0.001^{\mathrm{a}}$ & $0.931 \pm 0.001^{\mathrm{a}}$ & $0.935 \pm 0.001^{b}$ & $0.938 \pm 0.000^{b}$ \\
\hline & XTR & $0.968 \pm 0.001^{d}$ & $0.963 \pm 0.001^{\mathrm{d}}$ & $0.964 \pm 0.000^{\mathrm{d}}$ & $0.966 \pm 0.000^{c}$ & $0.969 \pm 0.001^{\mathrm{d}}$ & $0.971 \pm 0.000^{\mathrm{e}}$ & $0.974 \pm 0.001^{\mathrm{e}}$ \\
\hline & GRA & $0.941 \pm 0.001^{b}$ & $0.940 \pm 0.000^{b}$ & $0.942 \pm 0.000^{\mathrm{b}}$ & $0.943 \pm 0.001^{b}$ & $0.945 \pm 0.001^{\mathrm{c}}$ & $0.945 \pm 0.000^{\circ}$ & $0.949 \pm 0.001^{\mathrm{c}}$ \\
\hline
\end{tabular}

$\mathrm{CON}=$ Control, GLY= Glyphosate, ATR= Atrazine, GRA= Gramoxone, XTR= Xtravest, WK=Week. Columns with values that have the same letter show that there are no significant differences $(\mathrm{p} s 0.05)$ between the values; columns with values that have different letters show that there is a significant difference ( $\mathrm{s} \leq 0.05)$ between the values. 


\section{Changes in Fungal Counts $\left([\mathrm{CFU} / \mathrm{g}] \times 10^{4}\right)$ During Biodegradation}

Treatment with the herbicide types at the $2^{\text {nd }}$ week showed significant changes $(p \leq 0.009 ; p \leq 0.005$; $\mathrm{p} \leq 0.004 ; \mathrm{p} \leq 0.000 ; \mathrm{p} \leq 0.001$ ) in fungal counts at the $5^{\text {th }}, 10^{\text {th }}, 15^{\text {th }}, 20^{\text {th }}$ and $25^{\text {th }}$ days respectively (Table 5). Fungal counts increased from the $5^{\text {th }}$ day to the $20^{\text {th }}$ day and dropped on the $25^{\text {th }}$ day. xtravest had the lowest fungal count of $3.30 \times 10^{4} \mathrm{CFU} / \mathrm{g}$ at the $5^{\text {th }}$ day. At the $8^{\text {th }}$ week, significant changes $(\mathrm{p} \leq 0.001 ; \mathrm{p} \leq 0.002$; $\mathrm{p} \leq 0.001 ; \mathrm{p} \leq 0.005 ; \mathrm{p} \leq 0.002)$ in fungal counts occurred at $5^{\text {th }}, 10^{\text {th }}, 15^{\text {th }}, 20^{\text {th }}$ and $25^{\text {th }}$ days of incubation respectively. Fungal counts increased from the $5^{\text {th }}$ to the $15^{\text {th }}$ days and then decreased from the $20^{\text {th }}$ to the $25^{\text {th }}$ day. Xtravest had the highest fungal count value of $1.17 \times 10^{5} \mathrm{CFU} / \mathrm{g}$ at the $15^{\text {th }}$ day, while at the $5^{\text {th }}$ day gramoxone had the lowest fungal count value of $4.00 \times 10^{4} \mathrm{CFU} / \mathrm{g}$. At the $25^{\text {th }}$ day gramoxone recorded the lowest fungal count value of $3.30 \times 10^{4} \mathrm{CFU} / \mathrm{g}$.

\section{Changes in Fungal dry-weights During Biodegradation}

In Table 6 , at the $2^{\text {nd }}, 4^{\text {th }}$ and $8^{\text {th }}$ weeks, fungal dry weight values increased from the $5^{\text {th }}$ to the $20^{\text {th }}$ days and then dropped at the $25^{\text {th }}$ day. At the $2^{\text {nd }}$ week, fungal dry weight showed significant changes $(\mathrm{P} \leq 0.000)$ in values from the $5^{\text {th }}$ to the $25^{\text {th }}$ day (Table 6$)$. At the $20^{\text {th }}$ day xtravest recorded the highest fungal dry weight value of $0.020 \mathrm{~g}$. At the $25^{\text {th }}$ day gramoxone recorded the lowest fungal dry weight of $0.012 \mathrm{~g}$. There were significant changes $(\mathrm{p} \leq 0.000)$ in fungal dry weight values from the $5^{\text {th }}$ to the $25^{\text {th }}$ days at the $8^{\text {th }}$ week. Atrazine had the highest fungal dry weight value of $0.022 \mathrm{~g}$ at the $20^{\text {th }}$ day while gramoxone and glyphosate had the lowest value of $0.012 \mathrm{~g}$ at the $5^{\text {th }}$ day. At the $25^{\text {th }}$ day gramoxone had the lowest value of $0.012 \mathrm{~g}$ (Table 6).

Table 5: Changes in fungal counts $\left([\mathrm{CFU} / \mathrm{g}] \times 10^{4}\right)$ during biodegradation

\begin{tabular}{|c|c|c|c|c|c|c|}
\hline & & $5^{\mathrm{TH}}$ & $10^{\mathrm{TH}}$ & $15^{\mathrm{TH}}$ & $20^{\mathrm{TH}}$ & $25^{\mathrm{TH}}$ \\
\hline \multirow[t]{5}{*}{$2^{\mathrm{ND}} \mathrm{WK}$} & $\mathrm{CON}$ & $4.30 \pm 0.033^{\mathrm{a}}$ & $5.70 \pm 0.033^{\mathrm{ab}}$ & $8.00 \pm 0.058^{a}$ & $9.30 \pm 0.067^{\mathrm{ab}}$ & $8.70 \pm 0.033^{a}$ \\
\hline & GLY & $5.70 \pm 0.033^{b}$ & $7.70 \pm 0.033^{c}$ & $10.70 \pm 0.088^{b}$ & $13.70 \pm 0.033^{c}$ & $11.00 \pm 0.058^{b}$ \\
\hline & ATR & $4.30 \pm 0.033^{\mathrm{a}}$ & $6.30 \pm 0.033^{\mathrm{ab}}$ & $8.30 \pm 0.033^{\mathrm{a}}$ & $10.30 \pm 0.033^{b}$ & $8.70 \pm 0.033^{a}$ \\
\hline & XTR & $3.30 \pm 0.033^{\mathrm{a}}$ & $5.30 \pm 0.033^{\mathrm{a}}$ & $6.70 \pm 0.033^{\mathrm{a}}$ & $8.70 \pm 0.033^{\mathrm{a}}$ & $7.70 \pm 0.033^{a}$ \\
\hline & GRA & $4.30 \pm 0.033^{\mathrm{a}}$ & $6.70 \pm 0.033^{b c}$ & $8.00 \pm 0.000^{\mathrm{a}}$ & $12.70 \pm 0.033^{c}$ & $10.30 \pm 0.033^{b}$ \\
\hline \multirow[t]{5}{*}{$4^{\mathrm{TH}} \mathrm{WK}$} & $\mathrm{CON}$ & $3.30 \pm 0.033^{a}$ & $5.70 \pm 0.033^{\mathrm{ab}}$ & $6.70 \pm 0.033^{\mathrm{a}}$ & $4.70 \pm 0.033^{b c}$ & $3.00 \pm 0.000^{\mathrm{ab}}$ \\
\hline & GLY & $4.70 \pm 0.033^{b}$ & $6.00 \pm 0.000^{b c}$ & $6.30 \pm 0.033^{\mathrm{a}}$ & $4.00 \pm 0.000^{\mathrm{ab}}$ & $2.30 \pm 0.033^{a}$ \\
\hline & ATR & $4.30 \pm 0.033^{b}$ & $5.70 \pm 0.03^{\mathrm{ab}}$ & $7.00 \pm 0.058^{\mathrm{ab}}$ & $3.30 \pm 0.033^{\mathrm{a}}$ & $2.70 \pm 0.033^{\mathrm{a}}$ \\
\hline & XTR & $5.70 \pm 0.033^{c}$ & $7.00 \pm 0.058^{c}$ & $8.00 \pm 0.000^{b}$ & $5.70 \pm 0.033^{\mathrm{cd}}$ & $4.30 \pm 0.033^{c}$ \\
\hline & GRA & $3.00 \pm 0.000^{\mathrm{a}}$ & $4.70 \pm 0.033^{\mathrm{a}}$ & $6.70 \pm 0.033^{\mathrm{a}}$ & $5.00 \pm 0.000^{d}$ & $3.70 \pm 0.033^{b c}$ \\
\hline \multirow[t]{5}{*}{$6^{\mathrm{TH}} \mathrm{WK}$} & $\mathrm{CON}$ & $4.00 \pm 0.000^{\mathrm{ab}}$ & $4.70 \pm 0.033^{\mathrm{a}}$ & $4.70 \pm 0.033^{b}$ & $4.30 \pm 0.033^{b}$ & $2.70 \pm 0.033^{a}$ \\
\hline & GLY & $5.00 \pm 0.000^{b c}$ & $5.30 \pm 0.033^{\mathrm{ab}}$ & $5.70 \pm 0.067^{\mathrm{ab}}$ & $4.00 \pm 0.000^{\mathrm{ab}}$ & $2.30 \pm 0.033^{\mathrm{a}}$ \\
\hline & ATR & $5.30 \pm 0.067^{\mathrm{c}}$ & $5.70 \pm 0.120^{\mathrm{ab}}$ & $6.00 \pm 0.115^{\mathrm{a}}$ & $3.30 \pm 0.033^{\mathrm{a}}$ & $1.70 \pm 0.033^{\mathrm{a}}$ \\
\hline & XTR & $6.70 \pm 0.033^{d}$ & $7.00 \pm 0.058^{b}$ & $6.70 \pm 0.067^{c}$ & $4.70 \pm 0.033^{b}$ & $2.70 \pm 0.033^{\mathrm{a}}$ \\
\hline & GRA & $3.00 \pm 0.000^{\mathrm{a}}$ & $4.00 \pm 0.000^{\mathrm{a}}$ & $4.30 \pm 0.033^{\mathrm{ab}}$ & $4.00 \pm 0.000^{\mathrm{ab}}$ & $2.00 \pm 0.000^{\mathrm{a}}$ \\
\hline \multirow[t]{5}{*}{$8^{\mathrm{TH}} \mathrm{WK}$} & $\mathrm{CON}$ & $5.70 \pm 0.033^{b}$ & $6.70 \pm 0.033^{\mathrm{ab}}$ & $7.00 \pm 0.058^{\mathrm{a}}$ & $4.30 \pm 0.033^{\mathrm{a}}$ & $3.70 \pm 0.033^{\mathrm{a}}$ \\
\hline & GLY & $6.70 \pm 0.033^{b}$ & $7.70 \pm 0.033^{b}$ & $8.30 \pm 0.067^{\mathrm{a}}$ & $6.30 \pm 0.067^{\mathrm{ab}}$ & $4.70 \pm 0.033^{\mathrm{ab}}$ \\
\hline & ATR & $6.70 \pm 0.088^{b}$ & $7.70 \pm 0.088^{b}$ & $8.70 \pm 0.088^{a}$ & $7.30 \pm 0.088^{b c}$ & $5.70 \pm 0.067^{b c}$ \\
\hline & XTR & $8.70 \pm 0.033^{c}$ & $10.30 \pm 0.067^{c}$ & $11.70 \pm 0.033^{b}$ & $8.70 \pm 0.033^{c}$ & $6.30 \pm 0.033^{c}$ \\
\hline & GRA & $4.00 \pm 0.000^{\mathrm{a}}$ & $5.70 \pm 0.033^{\mathrm{a}}$ & $6.70 \pm 0.033^{\mathrm{a}}$ & $5.70 \pm 0.067^{\mathrm{ab}}$ & $3.30 \pm 0.033^{\mathrm{a}}$ \\
\hline
\end{tabular}


Table 6: Changes in fungal dry-weights during biodegradation

\begin{tabular}{|c|c|c|c|c|c|c|}
\hline & & $5^{\mathrm{TH}}$ & $10^{\mathrm{TH}}$ & $15^{\mathrm{TH}}$ & $20^{\mathrm{TH}}$ & $25^{\mathrm{TH}}$ \\
\hline \multirow[t]{5}{*}{$2^{\mathrm{ND}} \mathrm{WK}$} & $\mathrm{CON}$ & $0.010 \pm 0.000^{b}$ & $0.012 \pm 0.000^{b}$ & $0.014 \pm 0.000^{b}$ & $0.015 \pm 0.000^{b}$ & $0.015 \pm 0.000^{b c}$ \\
\hline & GLY & $0.012 \pm 0.000^{\mathrm{c}}$ & $0.015 \pm 0.000^{c}$ & $0.016 \pm 0.001^{c}$ & $0.018 \pm 0.001^{\mathrm{cd}}$ & $0.016 \pm 0.000^{\mathrm{cd}}$ \\
\hline & ATR & $0.013 \pm 0.000^{\mathrm{cd}}$ & $0.015 \pm 0.001^{\mathrm{c}}$ & $0.016 \pm 0.001^{c}$ & $0.017 \pm 0.001^{\mathrm{c}}$ & $0.015 \pm 0.001^{b}$ \\
\hline & XTR & $0.014 \pm 0.000^{\mathrm{d}}$ & $0.015 \pm 0.000^{c}$ & $0.017 \pm 0.000^{c}$ & $0.020 \pm 0.000^{d}$ & $0.017 \pm 0.000^{d}$ \\
\hline & GRA & $0.008 \pm 0.000^{\mathrm{a}}$ & $0.010 \pm 0.000^{\mathrm{a}}$ & $0.012 \pm 0.000^{\mathrm{a}}$ & $0.014 \pm 0.000^{\mathrm{a}}$ & $0.012 \pm 0.000^{\mathrm{a}}$ \\
\hline \multirow[t]{5}{*}{$4^{\mathrm{TH}} \mathrm{WK}$} & $\mathrm{CON}$ & $0.011 \pm 0.000^{\mathrm{a}}$ & $0.014 \pm 0.000^{\mathrm{a}}$ & $0.016 \pm 0.000^{\mathrm{a}}$ & $0.017 \pm 0.000^{\mathrm{a}}$ & $0.013 \pm 0.001^{\mathrm{a}}$ \\
\hline & GLY & $0.014 \pm 0.000^{\mathrm{b}}$ & $0.017 \pm 0.001^{b}$ & $0.019 \pm 0.001^{\mathrm{a}}$ & $0.020 \pm 0.000^{b c}$ & $0.014 \pm 0.001^{\mathrm{a}}$ \\
\hline & ATR & $0.015 \pm 0.000^{c}$ & $0.017 \pm 0.000^{\mathrm{b}}$ & $0.019 \pm 0.001^{\mathrm{a}}$ & $0.023 \pm 0.000^{c}$ & $0.019 \pm 0.000^{\mathrm{b}}$ \\
\hline & XTR & $0.024 \pm 0.000^{\mathrm{d}}$ & $0.026 \pm 0.001^{c}$ & $0.030 \pm 0.001^{b}$ & $0.032 \pm 0.002^{\mathrm{d}}$ & $0.021 \pm 0.000^{c}$ \\
\hline & GRA & $0.013 \pm 0.000^{b}$ & $0.015 \pm 0.001^{\mathrm{ab}}$ & $0.019 \pm 0.002^{\mathrm{a}}$ & $0.019 \pm 0.001^{\mathrm{ab}}$ & $0.015 \pm 0.001^{\mathrm{a}}$ \\
\hline \multirow[t]{5}{*}{$6^{\mathrm{TH}} \mathrm{WK}$} & $\mathrm{CON}$ & $0.013 \pm 0.000^{b}$ & $0.014 \pm 0.000^{\mathrm{ab}}$ & $0.015 \pm 0.001^{\mathrm{ab}}$ & $0.014 \pm 0.000^{c}$ & $0.010 \pm 0.000^{c}$ \\
\hline & GLY & $0.013 \pm 0.000^{b c}$ & $0.014 \pm 0.000^{b c}$ & $0.015 \pm 0.000^{\mathrm{ab}}$ & $0.013 \pm 0.000^{\mathrm{b}}$ & $0.010 \pm 0.001^{c}$ \\
\hline & ATR & $0.014 \pm 0.000^{c}$ & $0.015 \pm 0.000^{c}$ & $0.016 \pm 0.001^{b}$ & $0.013 \pm 0.001^{b}$ & $0.009 \pm 0.001^{\mathrm{c}}$ \\
\hline & XTR & $0.018 \pm 0.000^{d}$ & $0.018 \pm 0.000^{d}$ & $0.020 \pm 0.000^{c}$ & $0.016 \pm 0.000^{\mathrm{d}}$ & $0.006 \pm 0.001^{b}$ \\
\hline & GRA & $0.011 \pm 0.000^{\mathrm{a}}$ & $0.013 \pm 0.000^{\mathrm{a}}$ & $0.014 \pm 0.000^{\mathrm{a}}$ & $0.010 \pm 0.000^{\mathrm{a}}$ & $0.004 \pm 0.000^{\mathrm{a}}$ \\
\hline \multirow[t]{5}{*}{$8^{\mathrm{TH}} \mathrm{WK}$} & $\mathrm{CON}$ & $0.012 \pm 0.000^{\mathrm{a}}$ & $0.013 \pm 0.000^{\mathrm{a}}$ & $0.014 \pm 0.000^{\mathrm{a}}$ & $0.015 \pm 0.000^{\mathrm{a}}$ & $0.012 \pm 0.000^{\mathrm{a}}$ \\
\hline & GLY & $0.015 \pm 0.001^{b}$ & $0.017 \pm 0.000^{\mathrm{b}}$ & $0.019 \pm 0.000^{c}$ & $0.021 \pm 0.001^{b}$ & $0.016 \pm 0.000^{b}$ \\
\hline & ATR & $0.016 \pm 0.001^{b c}$ & $0.019 \pm 0.001^{\mathrm{c}}$ & $0.021 \pm 0.000^{\mathrm{d}}$ & $0.022 \pm 0.001^{b}$ & $0.020 \pm 0.001^{c}$ \\
\hline & XTR & $0.018 \pm 0.001^{\mathrm{c}}$ & $0.019 \pm 0.001^{\mathrm{c}}$ & $0.020 \pm 0.001^{\mathrm{d}}$ & $0.021 \pm 0.001^{\mathrm{b}}$ & $0.019 \pm 0.001^{c}$ \\
\hline & GRA & $0.012 \pm 0.000^{\mathrm{a}}$ & $0.014 \pm 0.001^{\mathrm{a}}$ & $0.016 \pm 0.000^{\mathrm{b}}$ & $0.014 \pm 0.000^{\mathrm{a}}$ & $0.012 \pm 0.000^{\mathrm{a}}$ \\
\hline
\end{tabular}

$\mathrm{CON}=$ Control, GLY $=$ Glyphosate, ATR $=$ Atrazine, GRA = Gramoxone, XTR=Xtravest, WK=Week. Columns with values that have the same letter show that there are no significant differences $(\mathrm{p} \geq 0.05)$ between the values; columns with values that have different letters show that there is a significant difference $(\mathrm{p} \leq 0.05)$ between the values.

\section{Residual Concentration of Herbicides Obtained from Soil Samples}

Fig. 1 shows the residual the residual concentration of herbicides obtained from herbicide treated soils. Residual concentration of herbicides increased significantly $(p \leq 0.024)$ from the $2^{\text {nd }}$ week to the $8^{\text {th }}$ week of treatment. There was also significant difference $(\mathrm{p} \leq 0.001)$ in residual concentration values of the herbicide types. The highest residual concentration value of $9.94 \times 10^{-1} \mathrm{ppm}$ was recovered from glyphosate treated soils at the $8^{\text {th }}$ week of treatment, and peak detection time of 11.37 mins. Also, at the $2^{\text {nd }}, 4^{\text {th }}$ and $6^{\text {th }}$ weeks of treatment it was noted that glyphosate treated soils had the highest residual concentration values of $4.13 \times 10^{-1} \mathrm{ppm}, 6.05 \times 10^{-1} \mathrm{ppm}$, and $8.62 \times 10^{-1} \mathrm{ppm}$ respectively (at peak detection times of $12.41 \mathrm{mins}$, $12.30 \mathrm{mins}$ and $17.53 \mathrm{mins}$ respectively) compared to other herbicide treated soils. The lowest residual concentration of $2.53 \times 10^{-1} \mathrm{ppm}$ (atrazine) was obtained from atrazine treated soils at the $2^{\text {nd }}$ week of treatment at peak detection time of $14.95 \mathrm{mins}$, while also at the $8^{\text {th }}$ week of treatment atrazine treated soils had the lowest concentration of atrazine $\left(6.67 \times 10^{-1} \mathrm{ppm}\right)$, at peak detection time of 15.26 mins compared to other herbicides at the $8^{\text {th }}$ week of treatment.

\section{Biodegradation of Herbicides by Bacteria and Fungi}

In Figure 2, the concentrations of the control were higher than the concentrations of the bacteria and fungi inoculated herbicides. There was significant reduction $(\mathrm{p} \leq 0.001)$ in the herbicide concentrations after degradation by bacteria and fungi. All herbicides inoculated with bacteria were found to contain lower concentrations of the corresponding herbicide compared to those that had been inoculated with fungi after 7 days of incubation on rotatory shaker incubator. The bacteria and fungi inoculated into each of the herbicides caused sharp reduction in herbicide concentrations compared to the control. The lowest herbicide concentration of $118.55 \mathrm{ppm}$ was obtained from atrazine inoculated with bacteria, while the highest 
herbicide concentration of $449.23 \mathrm{ppm}$ was obtained from xtravest inoculated with fungi at the $7^{\text {th }}$ day of incubation.

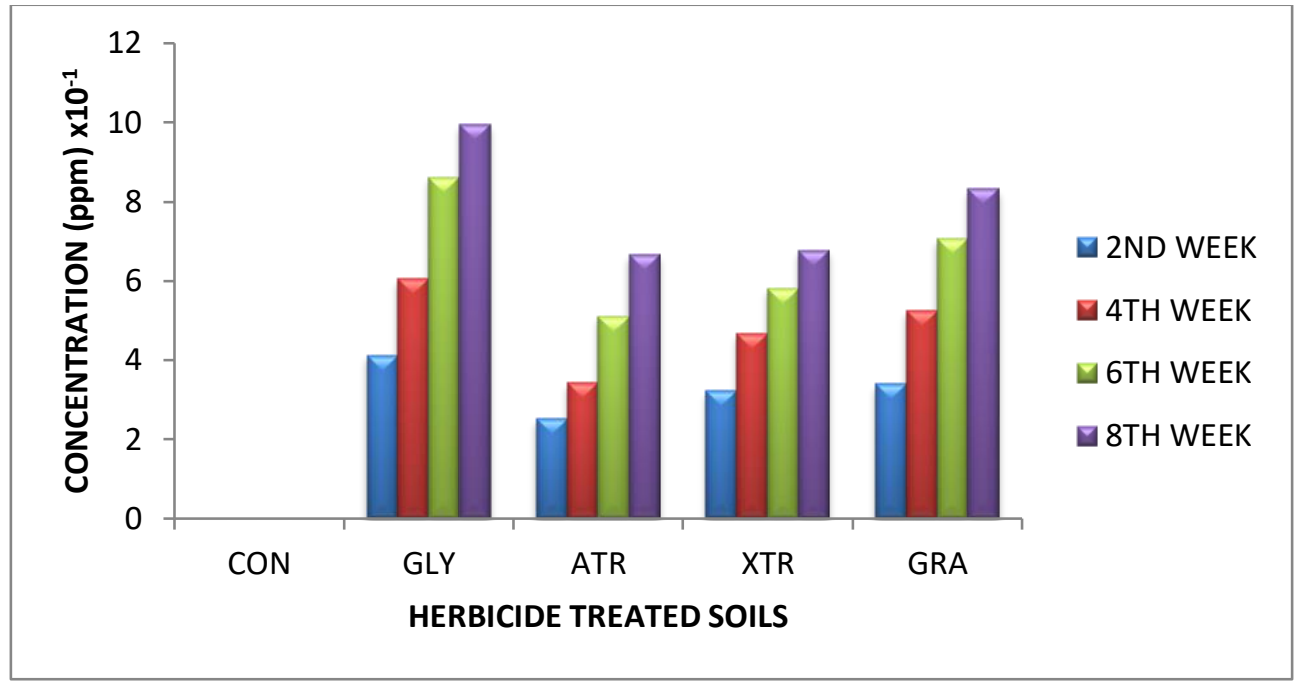

Figure 1: Residual concentration of herbicides obtained from soil samples.

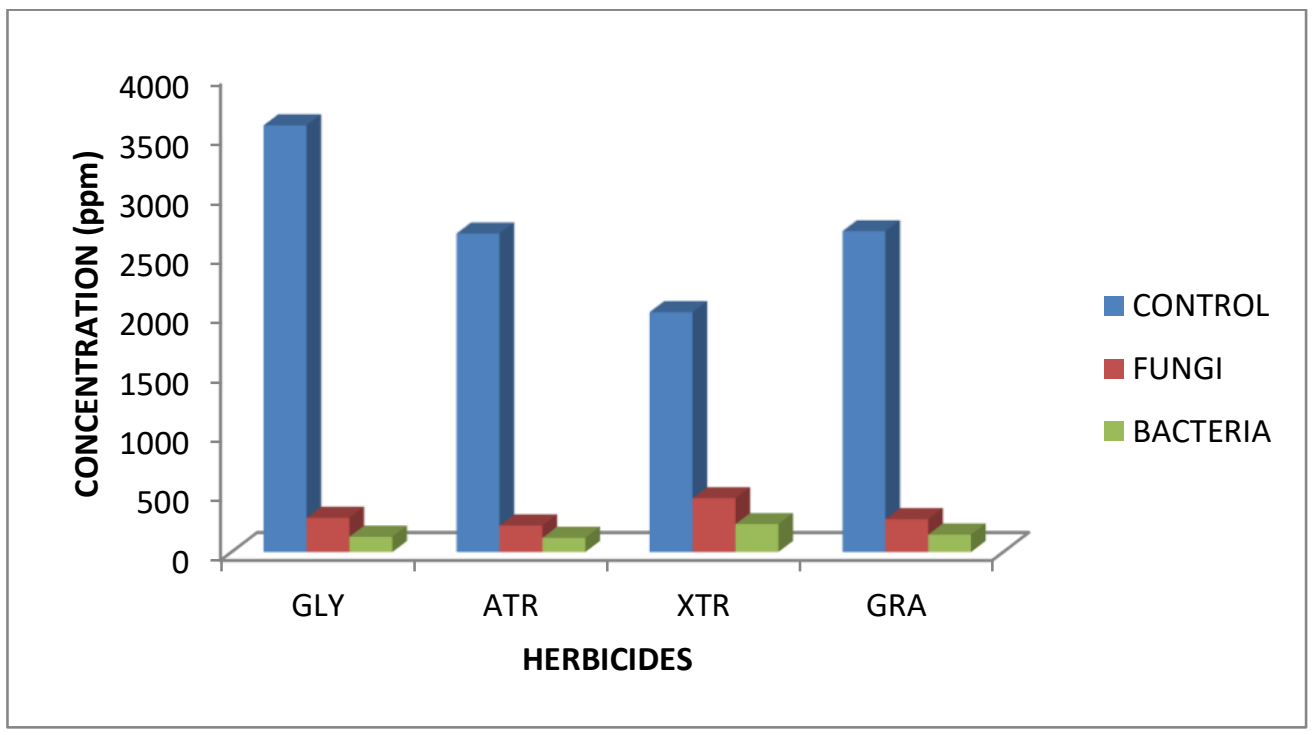

Figure 2: Biodegradation of herbicides by bacteria and fungi.

\section{DISCUSSION}

In this study $\mathrm{Zn}$ and $\mathrm{Fe}$ cations accumulated in soils after treatment with herbicides. Similar observation were also reported by Abah et al. (2012). The levels of Fe and $\mathrm{Zn}$ recorded in this study were found to be above critical limits of $10-20 \mathrm{mg} / \mathrm{kg} \mathrm{Fe}$ and $60-400 \mathrm{mg} / \mathrm{kg} \mathrm{Zn}$ which cause phytotoxicity in plants (FAO/WHO, 1976). This might be due to the chelation ability of these herbicides (allowing them to accumulate in this form in soils) where they form complexes with these metal co-factors essential for enzyme activities thus immobilizing them in soil reducing their availability to plants. Iron deficiency chlorosis is also becoming increasingly prevalent in cropping systems receiving frequent or prolonged applications of glyphosate (Ozturk et al., 2008). Cations in the soil solution are bonded to the surface of clay minerals by electrostatic interactions and can return in solution by the substitution of other cations or by dilution. The most representative exchange cations are $\mathrm{K}^{+}, \mathrm{Ca}^{2+}, \mathrm{Mg}^{2+}$, and $\mathrm{Na}^{+}$(Blasioli et al., 2011). 
The strong negative correlation of exchangeable $\mathrm{Ca}^{2+}$ with residual concentration of herbicides indicates that as the herbicides accumulated in the soils, as a result of successive treatment, there was concomitant reduction in exchangeable $\mathrm{Ca}^{2+}$ in the soils. The accumulation of $\mathrm{K}^{+}$in glyphosate treated soils occurred because $\mathrm{K}^{+}$is a constituent component of glyphosate chemical compound $\left(\mathrm{C}_{3} \mathrm{H}_{7} \mathrm{KNO}_{5} \mathrm{P}\right)$. The reduction in concentration of some soil minerals $\left(\mathrm{K}^{+}, \mathrm{Ca}^{2+}, \mathrm{Mg}^{2+}\right.$, and $\left.\mathrm{Na}^{+}\right)$in this study might have occurred as a result of leaching of the minerals in solution and the degradation of the herbicides consequent upon the utilisation of these soil minerals by soil microbes and also their resultant uptake by plants. Benzon et al. (2015) reported that the data on available $\mathrm{P}$, exchangeable $\mathrm{Mg}, \mathrm{Na}, \mathrm{Ca}$, and $\mathrm{K}$. CEC showed no significant difference among treatments. They also reported that relatively lower values were obtained compared to the control. Cucci et al. (2015) reported that the variations in available phosphorus and exchangeable potassium were negligible and not statistically different between the various treatments.

Herbicides used in this study persisted in soils upon successive treatments with the herbicides. GC analysis used in this study revealed that the herbicides accumulated in the soils throughout the period of treatment. This might be as a result of strong bonding interactions between the herbicides and soil organic matter resulting in their accumulation in soils. Glyphosate showed more persistence in soils as a result of its strong binding interaction with organic matter. Jilani and Khan (2004) reported that the residues of an applied pesticide may remain in the environment for variable periods of time.

The bacterial and fungal isolates used in the determination of the time utilisation of the herbicides showed appreciable growth in culture medium containing the herbicides as carbon source. The differences observed in the growth of the isolates in the media are indications of the differences between the organisms in tolerating the herbicides. This study showed that the bacterial and fungal isolates grew maximally on all the herbicides. The utilisation of herbicides in minimal salt medium have shown that none of the bacterial and fungal isolates exhibited lag phases, because the microorganisms used in this study are indigenous to the soil from which they were obtained and consequently have adapted to the herbicides used in treatment. Xtravest and glyphosate were better utilised by the indigenous bacteria and fungi in minimal salt medium compared to other herbicides tested in this study. According to Andy et al. (2017), microbial degradation of paraquat involves the action of some fungi and bacteria organisms. The genera of organisms that degrades paraquat include fungi: Rhizopus, Penicillium, Aspergillus and Mucor species and sole source of carbon and energy revealed that the isolates utilized paraquat at different rates. This indicates the varying ability of microorganisms to breakdown paraquat. In the work of Moneke et al. (2010), of the seven bacterial species they identified, two (Acetobacter sp. and P. fluorescens) were selected for further biodegradation studies based on their short lag phase and rapid utilisation of glyphosate. Many Pseudomonas species have been used extensively in the degradation and metabolism of glyphosate. Cheloufi et al. (2017) state that, glyphosate and 2.4-D have a negative effect on production of $\mathrm{P}_{2} \mathrm{O}_{5}$ and $\mathrm{NO}_{3}$ - in two Soils Types of the Bou Namoussa irrigable perimeter (Algerian Extreme Northeast), while herbicide 2.4-D exerts a more depressive action than that of Glyphosate towards microflora in both related soils from the point of view of texture and structure, loamy ground and other sandy in the irrigable perimeter of Bou Namoussa. Inhibition by these two herbicides decreases the two microbial activities concerning mineralisation of assimilable phosphorus and organic nitrogen in nitrate. The sharp reduction in herbicide concentrations after 7 days of incubation caused by the indigenous bacterial and fungal consortium indicates high rate of degradation by the indigenous bacteria and fungi, hence pointing to the ability of the microorganisms to use herbicides as carbon source. The bacterial consortium degraded herbicides faster than the fungal consortium because of their rapid rate of proliferation in aquatic environments. Bacteria degraded atrazine faster than any of the other herbicides used in this study. Moreno et al. (2007) reported that after 16 days of incubation there was, at a maximum, $50 \%$ of the added atrazine remaining. Shaner and Henry (2007) reported that there was approximately a 3- to 5-fold difference between the rates of degradation in the rapid assay compared to field dissipation. 


\section{CONCLUSION}

There were considerable reductions of exchangeable $\mathrm{Na}^{+}, \mathrm{K}^{+}$and $\mathrm{Mg}^{2+}$ in soils after herbicide treatment. The indigenous bacteria and fungi were able to utilize the herbicides as carbon source and consequently degrading them in-vitro. Continuous herbicide treatment should be avoided because of their ability to accumulate and persist in soils resulting in soil pollution and limiting essential nutrients available to plants. Indigenous microorganisms can be employed to remediate soils polluted by herbicides. Future studies on acceleration of biodegradation rates by indigenous microbial consortium should be examined.

\section{REFERENCES}

1. Abah, J., Akan, J.C., Uwah, E.I., Ogugbuaja, V.O. (2007). Determination of some anions levels in some tubers grown in Benue State, Nigeria. Trend in Applied Science Research, 3(2), 196-202.

2. Abah, J.A., Abdulrahaman, F.I., Ndahi, N.P. (2012). Study of the effects of chemical fertilizers and herbicides on the levels of some heavy metals and anions in soils and corn (Zea mays) growth in selected parts of Benue state, Nigeria. Journal of Physical Sciences and Innovation, 4, 62-72.

3. Andy, I. E., Edu, G. S., Bassey, I. U., Markson, A. A., Umana, E. I., Udo, S. E. (2017). Biodegradation of Paraquat. Journal of Biopesticides and Environment, 1, 80-85.

4. Australian Academy of Technological Sciences and Engineering (2002). Pesticide use in Australia. A review undertaken by the Australian Academy of Technological Sciences and Engineering. Anl Publishing, www.atse.org.au

5. Ayansina, A.D.V., and Oso, B.A. (2006). Effect of two commonly used herbicide on soil microflora at two different concentrations. African Journal of Biotechnology, 5 (2): 129-132.

6. Ayanthi, N., Priyantha, N., and Rodrigo, U (2008). Analytical Methods for the Investigation of Reactivity of Propanil. Journal of National Science Foundation, 36(3), 199-203.

7. Benzon, H.R.L., Rubenecia, M.R.U., Ultra, V.U., Lee, S.C. (2015). Chemical and Biological Properties of Paddy Soil Treated with Herbicides and Pyroligneous Acid. Journal of Agricultural Science 7: 1-10.
8. Blakemore, L.C., Searle, P.L., Daly, B.K. (1987). Methods for chemical analysis of soils. N.Z. Soil Bureau Sci. Rep. 80. Soil Bureau, Lower Hutt.

9. Blasioli, S., Braschi, I., Gessa, C.E. (2011). The fate of herbicides in soil: In Herbicides and the environment pp. 175-194. www.intechopen.com/download/pdf/pdfs_id/1258 6.

10. Chauhan, A.K. Das, A., Kharkwal, H., Kharkwal, A.C., Varma, A. (2006). Impact of microorganisms on environment and health, in A.K. Chauhan and A. Varma ed., Microbes: Health and environment.

11. Cheesbrough, M. (1984). Medical Laboratory Manual for Tropical Countries. Microbiology. Linacre House, Jordan Hill, Oxford. Vol.11.

12. Cheloufi, R., Messaadia, H., Alayat, H. (2017). Biodegradation of Herbicides by Pseudomonas aeruginosa in two Soils Types of the Bou Namoussa irrigable perimeter (Algerian Extreme Northeast): Effects on mineral nutrition (P2O5 and NO3 -). Journal of Materials and Environmental Sciences, 8(7), 2513-2521.

13. Clive, P. (2006). Effects of pesticides used in sugarcane cropping systems on soil Organisms and biological functions associated with soil health. A report prepared for the Sugar Yield Decline Joint Venture

14. Cucci, G., Lacolla, G., Crecchio, C., Pascazio, S., Giorgio, D.D. (2015). Impact of long term soil management practices on the fertility and weed 
flora of an almond orchard. Turkish Journal of Agriculture and Forestry, 39,1-9.

15. De-Lorenzo M. N., M., Domiguez A., Moldes D., Cameselle C., Sanroman, A. (2001). Enhanced ligninolytic enzyme production and degrading capability of Phanerochaete chrysosporium and Trametes versicolor. World Journal Microbiology and Biotechnology, 19, 665-669.

16. Ferrey, M.L., Koskinen, W.C., Blanchette, R.A., Burnes, T.A. (1994). Mineralisation of Alachlor by lignin-degrading fungi. Canadian Journal of Microbiology, 40 (9), 795-798.

17. Food and Agriculture Organisation/World Health Organisation (1976). List of maximum levels recommended for contaminants by joint FAO/WHO codex alimentary commission, 2nd series. CAC/FAI, Rome 3. Pp. 1-8.

18. Holt, J.G., Krieg, N.R., Sneath, P.H.A., Staley, J.T., Williams, S.T. (1994). Bergye's Manual of Determinative Bacteriology. 9th Ed. Williams and Wilkins, Baltimore, Maryland, USA.

19. Jilani, S., Khan, M.A. (2004). Isolation, characterisation and growth response of pesticide degrading bacteria. Journal of Biological Sciences, $4,15-20$

20. Kruger, E.L, Rice, P.J., Anhalt, J.C., Anderson, T.A., and Coats, J.R. (1996). Use ofundisturbed soil columns under controlled conditions to study the fate of [14C] diethylatrazine. Journal of Agriculture and Food Chemistry, 44, 1144-1149.

21. Maynard, E. (2000) Heavy metal contamination in soils of urban highways, Cincinati, Ohio. Journal of Water and Soil Pollution, 133, 293-314.

22. Moneke, A.N., Okpala, G.N., Anyanwu, C.U. (2010). Biodegradation of glyphosate herbicide in vitro using bacterial isolates from four rice fields. African Journal of Biotechnology, 9 (26), 40674074.

23. Moreno, J.L., Aliaga, A., Navarro, S., Hernandez, T., Garcia, C. (2007). Effect of atrazine on microbial activity in semiarid soil. Applied Soil Ecology, 35, 120-127.

24. Ozturk, L., Yazici, A., Eker, S., Gokmen, O., Roemheld, V., Cakmak, I. (2008). Glyphosate inhibition of ferric reductase activity in iron deficient sunflower roots. New Phytology, 177, 899-906.

25. Sethi, S., Pophle, S., Varte, N., Salve, C., Waghela, S. (2015). Microbial population response exposed to Different pesticides. International Journal of Scientific Engineering and Applied Science, 1(5), 250-255.

26. Shaner, D., Henry, W.F. (2007). Field history and dissipation of atrazine and metolachlor in Colorado. Journal of Environmental Quality, 36, 128-134.

27. Souza, J. B. G., Re-Poppi, N., Raposo Jr., J. L. (2012). Characterization of pyroligneous acid used in Agriculture by Gas Chromatography-Mass Spectrometry. Journal of Brazil Chemical Society, 23(4), 610-617.

28. Tahar, W., BordJiba, O., Mezedjri, L. (2017). Impact of two Pesticides on soil Physicochemical Characteristics and the Biological Activity. Journal of Chemical and Pharmaceutical Sciences, 10(2), 803-808

29. Trimurtulu, N., Ashok, S., Latha, V., Subramanyeswara R.A. (2015). Influence of PreEmergence Herbicides on the Soil Microflora during the Crop growth of Blackgram, Vigna mungo.L. International. Journal Current Microbiology and Applied Sciences, 4(6), 539-546

30. Tripathi, S.K., Sumida, A., Ono, K., Shibata, H., Uemura, S., Kodama, Y., Hara, T. (2006). Leaf litter fall and decomposition of different above-and below ground parts of birch (Betula ermanii) tree and dwarf bamboo (Sasa kurilensis) shrub in a young secondary forest of Northern Japan, Biology and Fertility of Soils, 43, 237-246.

31. United States Department of Agriculture, Soil Conservation Service (1972, 1982). Soil Survey 
Laboratory Methods Manual. Soil Survey Investigations Report no. 1. United States Department of Agriculture, Washington, D.C. 